\title{
ACOUSTIC EMISSION STUDIES ON ENVIRONMENTAL CRACKING IN BRASSES
}

U. K. Chatterjee*, S. C. Sircar* and G. S. Agrawal** ${ }^{*}$ Department of Metallurgical Engineering, IIT Kharagpur, India
${ }^{*}$ Department of Metallurgical, $R$. E. College, Rourkela, India

ABSTRACI

Acoustic emission simals during the crecking of alpha and alpha-beta brass cup specimens in mercurous nitrate solution, liquid mercury and anmoniacal solution have been recorded as

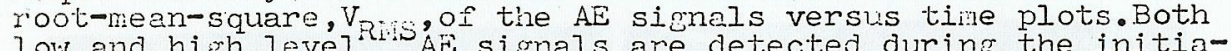
tion and proparration of cracks. In different environments the plots have disolayed charecteristic patterns. The observed plots have disslased chas cteristic patters. difference in cracking mechanism of brass in these three media.

KEY UORDS

Acoustic emission ; stress corrosion cracking ; mercury cracking; brass.

INTRODUCTION

A naterial under oins crack growth both renerates and transmits a sinnal (acoustj.c emission) which can be detected by suitable instrunentation and whose source can be located by using seismic tecininues. Kaiser (1953) reported first comprenensive investigation of acoustic enission (Ai). In the sixties the use of gation acouste ent.sion as a non destructive inspection techna structures.

The association of a brittle fracture step in the mechanism of stress corrosion cracking led some investigators(Van Rooyen, 1960 stress corrosion cracking led some investigators (Van Rooyen, 1960 ; Pardue, Beck and Fontina, 1951) to detect any sound generated dur ng cracking. Pardue, Beck and Fontena (1961) reor failure a not during an inter reinular failure and enphasized 
on alf arerenoe in mechanlsm in these two types of failure. liartwower and co-workers(1972) detected the crack initiation through aoouatio emlssion studies in high strength steels and IItanium. Okada, Xukawa and Tamma (1976) reported of a correlation of acoustic emission counts and fractographic detection of quasi cleavage crack in high strength steels in boiling nitrate solut1ons. Pugh and co-workers $(1975,1977)$ reported the evidence for the discontinuous nature of the growth of single cracks in $\mathrm{Mg}-\mathrm{Al}$ and admiraltry metal from acoustic emission studies. They found discrete acoustic emission signals and calculated the crack velocities from crack advance distance and average time interval between discrete emissions, which showed reasonable agreement with the values of crack velocities determined by direct exper1ment. Bentley(1976) reported on acoustic emission from stress corrosion cracking in 316 stainless steel.

De Michelis, Farina and Sala (1981) made use of the application of acoustic emission in the study of kinetics of fracture of brass in mercurous nitrate solution. They detected both low and high level AE signals during fracture nucleation and progress and some characteristic patterns of acoustic activity were recog nised and correlated to specific stages of the fracture process.

The literature shows that, though limited in number, the application of acoustic emission technique has been made with diversified aims in the field of environmental cracking of metals. The work of De Michelis and colleagues (1981) is very significant in that it correlates the acoustic emission patterns to the cracking process. A material like brass is prone to various types of environmental cracking; it shows stress corrosion cracking in aminonlacal environments and also shows stress cracking in both liquid mercury as well as in mercurous nitrate solution. In an earlier paper AE technique on cracking of brasses was employed (Agrawal, chatterjee and Sircar, 1984). The present work is an attempt to make use of the acoustic emission patterns to identify the difference in the mechanism of the cracking processes in these three environients.

\section{EXPERIMENTAL}

Alpha brass and alpha-beta brass sheets having $36 \% \mathrm{Zn}$ and $40 \% \mathrm{Zn}$ respectively, have been used in the present study. These were annealed at 500 C for 2 hours. Round samples of $65 \mathrm{rm}$ diameter were cut from these sheets. For studies in cold-worked condition the sheets vere first cold-rolled to give the requisite reduction in thickness and then the samples were cut. All the samples were subjected to deep drawing, accordino to the Erichsen procedure (sphere diameter of $20 \mathrm{~mm}$ ) upto $3 / 4$ of the maximum sag
at rupture.

The cup specimens were kept horizontally over four rubier prods fixed to a wooden board in order to minimise extraneous signals. The AE transducer was acoustically coupled to a plane corner of the specimen with a thin silicon grease layer, and fixed with adhesive tape. Acquisition of the $A E$ data started immediately after the cavity had been fllled with the testysolution. The plots of the root mean square of the $\mathrm{AP}$ signa, RMS, as a function of time were recorded on paper, the start and end of the activity were noted. All the plots were made at a total amplification of $148 \mathrm{~dB}$.

The ammoniacal solution used was one of Hattsson type (irattsson, 1967 ) containin $0.08 \mathrm{~g}$. atom $/ 1$ of copper and 3.2 . mole $/ 1$ of 117 in amal gramated state.

RESULTS

Armealed samples of both alpha and alpha-beta brass did not crack in mercurous nitrate solution. The V RMS vs. time plots (Fir.l) chlitude discomected simals appeared aftervards and continued tiliz the $\mathrm{AE}$ experinents were discontinued.

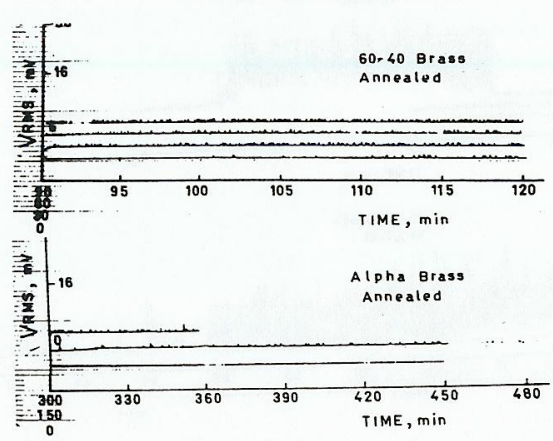

FiÉ.1: AE signals in $\mathrm{HENO}_{3}$ solution. for annealed jorasi.

In contrast to annealed samples, the cold worked samples gave cracking in $\mathrm{HgNO}_{3}$ solution and the $\mathrm{A}$ I plots were distinctly different(Fig. 2 and Fis. 3). The onset of cracking was marked by a high amplitude peak, often accompanied by a visible crack in the sample. A number of such peaks were obtained in the plot during the course of experiment and the visible cracks, mostly radial, were also quite a few in number. In the case of alpha beta brass ( $F i \mathrm{~B} \cdot 3$ ) these peaks occurred in close succession showing intensive A activity in this case. The cracks were found to projress in steps during this high activity period viewed microscopically.

In liquid mercury, alpha brass showed no cracking either in aninealed or in cold-worked concition. The alpha-beta brass also did not crack in annealed or in 15\% cold-rorked state, but cracking was encountered in samples cold woxked above 20\%. Large peaks were encountered in the $\mathrm{V}_{\mathrm{R} W \mathrm{~W}} \mathrm{~V}$. time plots within a few 


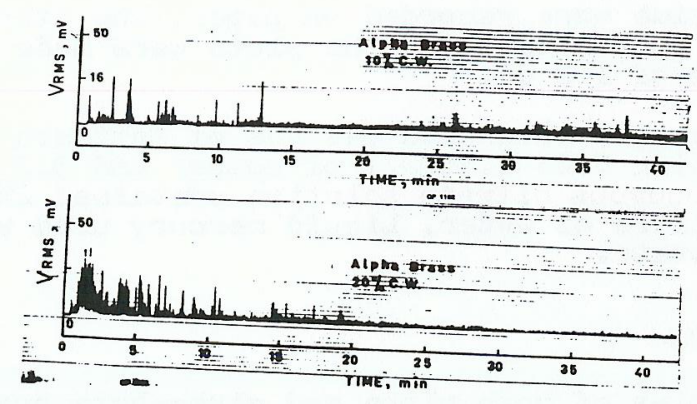

Fig. 2: AE signals for cracking of alpha brass in $\mathrm{HgNO}_{3}$ soln.

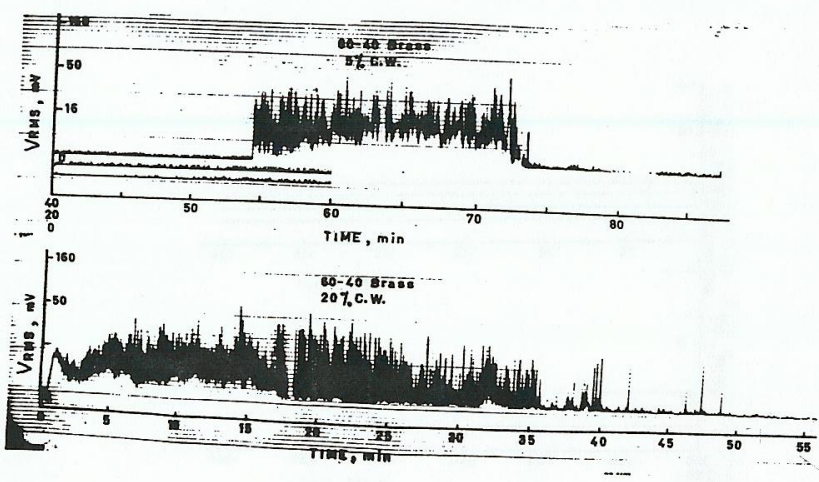

Fig. 3: AE signals for cracking of alphabeta brass in $\mathrm{HgNO}_{3}$ solution.

seconds to 5 minutes' exposure (Fig. 4). The cracks were immedian propagation was instantaneous. The peaks cases were much higher compared to those obser of in $\mathrm{KgNO}_{3}$ solution and their number was also less. The range in intense activity showing successive peaks were al so range cracking was intergranular in this case as the

In Mattsson solution, annealed and $20 \%$ cold worked samples were used, which gave cracking in this medium, but re low as can be seen from Figs. 5 and 6 . The cracks were maintained even onset of $A E$ activity and the $A E$ signals were vilntalned even after 10 hours with the simultaneous growth of islole cracks. Although the AE signals were similar in and alpha-beta brasses, the cracking the former was intergranular
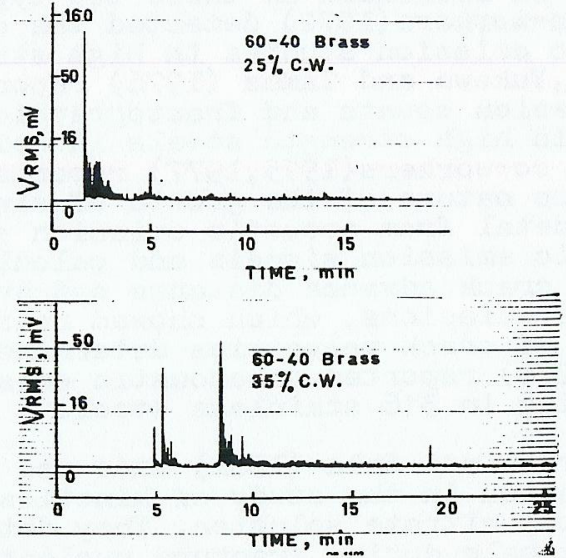

Fig. 4: AE signals for cracking of

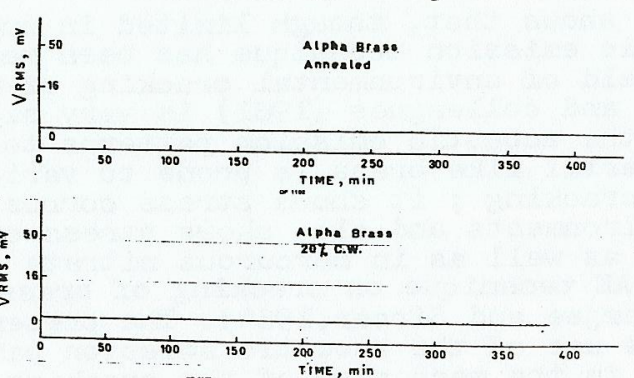

Fig. 5: AE signals for corrosion cracking of alpha brass in Mattsson soln.

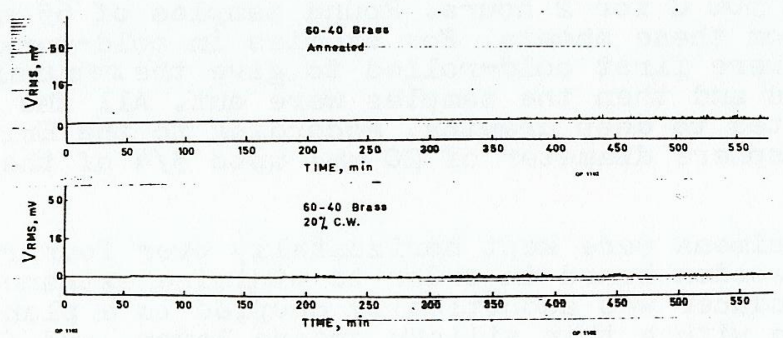

Fig. 6: AE signals for stress corrosion cracking of alpha-beta brass in Mattsson solution. 


\section{DracusaroN}

The rosulta show that, in general, the onset of cracking can be identried with the appearance of a peak in the plot, which is The process 1 t coustic energy release during the cracking process. helght of the peaks and the have varled widely in the

The picture of the cracking process of brass in $\mathrm{HgNO}_{3}$ solution, (Agrawal 1984) propagating throug the cracks in liquid mercury the plastic deform of cemented mercury whereas visualised to fa the petal has been initiate a crack, whith certain sites to of mercury penetration. proth as a result stages of stress corrosion solution, on the other hand and Sherbini,1978) to be electrocheen shown (Sircar, Chatter jee sed models get support from the acoustic emission signals obser-

In $\mathrm{HgNO}_{3}$ solution, the high amplitude peaks and their closed of attack. tion of the local stress and each crack is limited by the relaxais also probable that ss and a fresh crack starts thereafter. It less viscous than the prevents the mercury to reach mercury, inside the growing crack crack is halted. The the provides numerous sites for a cess is repeated so long as and this proenough to sustain close association have been observed a result, multiple peaks in in such case is much less than in release of much less less than in liquid mercury because of

In the case of cracking in liquid mercury, on the other hand, peaks of higher amplitudes have been encountered. They are,never theless, discrete and fewer compared to those in HgNO solution The visual observation on progress of crack correlates well with ss of gnals encountered, which clearly indicates the fast progrepenetration without any due to decohesive action of mercury

In Mattsson solution, the peaks observed have been of much lower amplitude, but such peaks were quite large in number. This indisimilar to the situatinitiation at a large number of sites, tion stage being elo propagaa brittle fracture is emission due to by some investigators (Van Rooyen Fontana, 1961) that AE signalsyen, 1960 ; Pardue, Beck and transgranular SCC, which is the case of fracture step, but in the present to involve a mechanical have been obtained with al present sudy almost similar results intergranular and transgranular craping
The low amplitude acoustic signals obtained for annealed alpha and alpha-beta brass in $\mathrm{HgNO}_{3}$ solution look similar to those obtained in Mattsson solution. In the former case cracking is, however, absent, and the results appear to be somewhat confusing. It is sometimes claimed (Gerberich and Hartbower, 1967; Dunegan and co-workers,1968,1971) that AE studies could well be utilised for predicting the possibility for the progress of an existing rlaw as a crack and in such cases the $\mathrm{AE}$ signals can be registered much before the appearance of a visible crack. But in the present study, the cracks usually appeared simultaneously with the onset of $A E$ signals. It is, however, possible that the low peaks encountered in the annealed materials in $\mathrm{HgNO}_{3}$ solution are indicative of the possibility of fracture in the se materials with longer exposures or at higher stresses.

\section{CONCLUSIONS}

The acoustic emission patterns encountered in the environmental cracking of brass in $\mathrm{HgNO}_{3}$ solution, in liquid mercury and in ammoniacal solution are different in the three media. The observed patterns support the proposed model of mercurous nitrate cracking involving a slow electrochemical initiation step, that of stress corrosion cracking having both initiation and propagation stages as electrochemical and that of mercury cracking as a rapidly occurring brittle fracture process.

\section{REFEREINCES}

Agrawal,G.S., Chatterjee,U.K., and Sircar,S.C.(1984). Trans.Indian Inst.Metais, To be published.

Agrawal,G.S.(1984).Ph.D.Thesis, IIT Kharacpur.

Bentley,P.G. (1976), 5 th Meeting Eur.Working Grp. on Acoustic Emission,Roskilde, Denmark.

Chakrapani,D.G. and Pugh,E.N. (1975). Met. Trans.A, 6A, 1155. Dunegan, H.I., Harris, D.O. and Tatro, C.A.(1968). Engineering $F$ Fracture Mechanics, 1,105

Dunegan, H.I. and Tatro, C.A. (1971). Techniques of Material Research, 5, 273

De Michelis, C., Farina, C. and Sala, C.(1981). Br.Corros.J. 16,20 .

Gerberich,W.W. and Hartbower,C.E.(1967). Proceedings of Conference on Fundamental Aspects of Stress Corro

Hartbower, C.E., Reuter, W.G., Morais, C.F. and Crimnins, P. P. (1972). ASTM STP 505, pp. 187.

Kaiser,J. (1953) Arch. Eisenhuttenwesen, $24,43$.

Mattss on, E. (196i) . Electrochim.Acta 3,279 ,

. Corrosion, 32,201

Parcue, w.H. Beck,F.H. and Fontana, G. (1961). Trans. Am.Soc.

Pugh, E.N. $\frac{54}{\text { and }}$ 539.

Westwood (Eds.), Mechanism of Environinent Selnsitive Cracking of Materials, The $\frac{\text { Metals Society, London , pp. } 471 .}{\text { Metal }}$ Sircar,S.C.'Chatterjee, U.Ko and Sherbini, G.M. (1978). Proceedings Van Rooyen, D. (1960). Corrosion, 16, 421 t. 